\title{
TEMPERAMENT AND CHARACTER TRAITS IN PATIENTS WITH BIPOLAR DISORDER AND ASSOCIATIONS WITH COMORBID ALCOHOLISM OR ANXIETY DISORDERS
}

\author{
Fabiano G. Nery ${ }^{a, b}, c$, John P. Hatch ${ }^{a}, d$, David C. Glahn ${ }^{a}$, Mark A. Nicoletti ${ }^{a}, b$, E. Serap \\ Monkul $^{a, b}, e$, Pablo Najt ${ }^{a, b}$, Manoela Fonseca ${ }^{a, b}$, Charles L. Bowden ${ }^{a}$, C. Robert \\ Cloninger ${ }^{f}$, and Jair C. Soares ${ }^{a, b, g}$ \\ aDepartment of Psychiatry, The University of Texas Health Science Center at San Antonio, San Antonio, \\ Texas, USA.
}

bSouth Texas Veterans Health Care System, Audie L. Murphy, San Antonio, Texas, USA.

cBipolar Disorder Research Program, Department of Psychiatry, University of São Paulo Medical School, São Paulo, Brazil.

dDepartment of Orthodontics, The University of Texas Health Science Center at San Antonio, Texas, USA.

eDepartment of Psychiatry, Dokuz Eylul University School of Medicine, Izmir, Turkey.

fDepartment of Psychiatry, Washington University School of Medicine, St. Louis, Missouri, USA.

gCenter of Excellence for Research and Treatment of Bipolar Disorders (CERT-BD), Department of Psychiatry, University of North Carolina School of Medicine, Chapel Hill, North Carolina, USA.

\begin{abstract}
Temperament and character traits may determine differences in clinical presentations and outcome of bipolar disorder. We compared personality traits in bipolar patients and healthy individuals using the Temperament and Character Inventory (TCI) and sought to verify whether comorbidity with alcoholism or anxiety disorders is associated with specific personality traits. Seventy three DSM-IV bipolar patients were compared to 63 healthy individuals using the TCI. In a second step, the bipolar sample was subgrouped according to the presence of psychiatric comorbidity (alcoholism, $n=10$; anxiety disorders; $\mathrm{n}=23$; alcoholism plus anxiety disorders, $\mathrm{n}=21$; no comorbidity, $\mathrm{n}=19$ ). Bipolar patients scored statistically higher than the healthy individuals on novelty seeking, harm avoidance and self-transcendence and lower on self-directedness and cooperativeness. Bipolar patients with only comorbid alcoholism scored statistically lower than bipolar patients without any comorbidity on persistence. Bipolar patients with only comorbid anxiety disorders scored statistically higher on harm avoidance and lower on self-directedness than bipolar patients without any comorbidity. Limitations of this study include the cross-sectional design and the small sample size, specifically
\end{abstract}

\footnotetext{
(C) 2007 Elsevier Ltd. All rights reserved.

Corresponding author: Jair C. Soares, M.D., Yeargan Distinguished Professor of Psychiatry. Director, UNC Center of Excellence for Research and Treatment of Bipolar Disorders (CERT-BD). Department of Psychiatry, University of North Carolina School of Medicine. 10616 Neuroscience Hospital CB \# 7160. Chapel Hill, NC, USA. 27599-7160. Phone: (919) 966.8832. Fax : (919) 843-3950. E-mail: E-mail: jsoares@med.unc.edu .

Publisher's Disclaimer: This is a PDF file of an unedited manuscript that has been accepted for publication. As a service to our customers we are providing this early version of the manuscript. The manuscript will undergo copyediting, typesetting, and review of the resulting proof before it is published in its final citable form. Please note that during the production process errors may be discovered which could affect the content, and all legal disclaimers that apply to the journal pertain.

Previous presentation: $60^{\text {th }}$ Annual Meeting of the Society of Biological Psychiatry. Atlanta, GA. 2005.
} 
in the analysis of the subgroups. However, our results suggest that bipolar patients exhibit a different personality structure than healthy individuals and that presence of psychiatric comorbidity in bipolar disorder is associated with specific personality traits. These findings suggest that personality, at least to some extent, mediates the comorbidity phenomena in bipolar disorder.

\section{Keywords}

bipolar disorder; personality; comorbidity; alcoholism; anxiety disorders; psychopathology

\section{Introduction}

"We are, therefore, led to the conclusion, that there are certain temperaments which may be regarded as rudiments of manic-depressive insanity. They may throughout the whole of life exist as peculiar forms of psychic personality without further development; but they may also become the point of departure for a morbid process which develops under peculiar conditions and runs its course in isolated attacks." Emil Kraepelin, in Manic Depressive Insanity

Bipolar disorder is a severe and debilitating psychiatric disorder with an unpredictable course and a high impact on social and occupational life. Historically, personality has been considered a vulnerability factor or a behavioral marker for bipolar disorder (Kraepelin, 1976; Angst, 2000). It also has been proposed that personality may shape the clinical presentation or outcome of affective disorders or that personality may be modified by repeated mood episodes (Akiskal et al., 1983). Bipolar disorder and specific personality traits may even share a common familial or genetic predisposition (Staner et al., 1998; Blairy et al., 2000; Rogers et al., 2004).

Studies that evaluated the personality of bipolar patients using the Temperament and Character Inventory (TCI) reinforced these concepts. The TCI is based on a psychobiological model of personality, which assumes that personality derives from the dynamic interaction among four temperament and three character traits (Cloninger et al., 1993). Temperament traits (novelty seeking, harm avoidance, reward dependence and persistence) represent basic emotional responses, which are manifested early in life, are stable throughout life and are moderately heritable. Character traits (self-directedness, cooperativeness and self-transcendence) represent concepts about self and personal relations, which are regulated by supervisory cognitive processes that develop throughout life (Cloninger et al., 1994; Cloninger et al., 2005). When compared to healthy individuals, bipolar patients achieve higher scores on novelty seeking (Young et al., 1995; Osher et al., 1999; Evans et al., 2005), harm avoidance (Young et al., 1995; Osher et al., 1996; Engstrom et al., 2004a; Evans et al., 2005) and reward dependence (Osher et al., 1996), and lower scores on persistence (Osher et al., 1996; Osher et al., 1999) and self-directedness (Engstrom et al., 2004a; Evans et al., 2005). In bipolar disorder, higher scores on harm avoidance were also associated with early onset of disease and fewer suicide attempts (Engstrom et al., 2003; Engstrom et al., 2004b).

It is also noteworthy that bipolar disorder is associated with high rates of comorbidity with other Axis I disorders, including alcoholism and anxiety disorders (Regier et al., 1990; Kessler et al., 1997; McElroy et al., 2001; Simon et al., 2004). In bipolar disorder, lifetime prevalence of alcoholism can reach 33\% to 46\% (Regier et al., 1990; McElroy et al., 2001), while rates of anxiety disorders reach $42 \%$ to $51 \%$ (McElroy et al., 2001; Simon et al., 2004). Personality is an important factor in each of these isolated disorders. Alcoholic patients have significantly higher novelty seeking scores and lower self-directedness scores compared to healthy individuals (Basiaux et al., 2001; Le Bon et al., 2004) and higher novelty seeking is associated with poly-substance abuse in drug addicts (Conway et al., 2003). Patients with anxiety disorders 
have higher scores on harm avoidance and lower scores on novelty seeking and selfdirectedness compared with healthy individuals (Lyoo et al., 2001; Ball et al., 2002; Pélissolo et al., 2002).

Although specific personality profiles occur in patients with bipolar disorder as well as those with alcohol and anxiety disorders, previous research has not specifically addressed the question of whether personality is associated with the occurrence of comorbidity in bipolar disorder. In this study, our objectives were: 1) to compare the personality structures of bipolar patients and healthy individuals using the TCI; 2) to compare the personality structure of bipolar patients with and without comorbid alcoholism or anxiety disorders. Based on previous studies, our first hypothesis was that bipolar patients would differ from healthy individuals on some personality traits, particularly higher levels of novelty seeking and harm avoidance. Our second hypothesis was that bipolar patients without any comorbid condition would present a different personality structure when compared to bipolar patients with comorbid alcoholism or anxiety disorders. If personality structure is related to comorbidity, then knowing the manner in which personality traits are manifested in bipolar disorder patients with and without comorbidity might help to disentangle the factors implicated in the etiology and clinical course of this disorder and assist in optimizing research and treatment planning.

\section{Material and methods}

\subsection{Sample}

This analysis included a sample of 136 subjects. All of the bipolar patients and healthy controls were residents of the San Antonio metropolitan area or surrounding cities. The subjects were recruited through local media advertisements and flyers posted in the medical center. Inclusion criteria for the bipolar patients were: diagnosis of bipolar disorder, type I or II and age of 18 to 99 years. Any mood state was allowed. Exclusion criteria for bipolar subjects were presence of any other Axis I diagnosis except lifetime anxiety disorders and/or alcoholism, presence of significant medical problems and presence of neurological disorders. The exclusion criteria for healthy individuals were presence of any past or current Axis I or II psychiatric disorder, presence of any current neurological or medical problems and presence of any Axis I diagnosis in first-degree relatives. All investigation was conducted in accordance with the Declaration of Helsinki, and the study was approved by the local institutional review board. After complete description of the study to the subjects, written informed consent was obtained.

\subsection{Measures}

The diagnostic assessments were conducted using the Structured Clinical Interview for Axis I DSM-IV Disorders (SCID), versions for patients and non-patients (First et al., 2002). The 21item Hamilton Depression Rating Scale (HDRS) and the Young Mania Rating Scale (YMRS) were administered to all bipolar patients and healthy individuals to assess severity of mood symptoms (Hamilton, 1976; Young et al., 1978).

Personality traits were assessed using the Temperament and Character Inventory (TCI) (Cloninger et al., 1994). The TCI is a self-report questionnaire composed of 240 true-false items designed to measure individual differences on 7 dimensions of temperament and character. The psychometric properties of the TCI have been extensively evaluated in normative and clinical samples (Cloninger et al., 1994).

\subsection{Statistical analyses}

Exact $X^{2}$ tests for cross tabulated qualitative data and Mann-Whitney $U$ test or analysis of variance (ANOVA) for ordinal and interval scale data were used to evaluate the clinical and demographic variables between bipolar patients and healthy individuals or among subgroups 
of bipolar patients with and without comorbidity. Analysis of covariance (ANCOVA) with age and gender as covariates was used to compare the mean TCI dimension scores between bipolar patients and healthy individuals, and to compare effects of medication status on mean TCI dimension scores between medicated and unmedicated patients. Spearman correlations or partial correlations were used to examine the bivariate associations between the TCI personality traits and specific clinical characteristics of the subjects. To investigate the effect of comorbidity on the TCI dimension scores in bipolar patients, the patient sample was divided in 4 subgroups according to the presence of comorbid alcoholism and/or anxiety disorders [bipolar without any comorbidity, bipolar with only comorbid alcohol, bipolar with only comorbid anxiety disorder, bipolar with dual comorbidity (alcoholism plus anxiety disorder)]. The mean TCI dimension scores among these subgroups were compared using ANCOVA with age, gender and mood state (as measured by HDRS and YMRS) as covariates. All reported means and standard deviations are the unadjusted values. The level of significance was set at 5\%; Sidak adjustment for multiple comparisons among subgroups was used. SPSS (SPSS, Inc., Chicago, IL) version 12.0 was used to do all analyses.

\section{Results}

\subsection{Demographic and clinical characteristics}

Seventy three DSM-IV bipolar patients (mean age \pm S.D.: $37.8 \pm 11.5$ y; males: $35.6 \%$ ) were compared to 63 healthy individuals $(34.5 \pm 10.5 \mathrm{y}$; males: $31.7 \%)$. There was no statistical difference between bipolar patients and healthy individuals regarding age $(p=0.06$, Mann Whitney $\mathrm{U}$ test $)$ and gender $(\mathrm{p}=0.59$, Fisher Exact test). The bipolar sample was composed predominantly by bipolar disorder type I $(87.7 \%)$, in a major depressive episode $(61.6 \%)$, with a HDRS score of $16.5 \pm 9.0$ and YMRS mean score of $8.8 \pm 7.1$. Fifty six (76.7\%) of the bipolar sample was in use of medication (mood stabilizers, antidepressants or anxiolytics). There were no main effects of medication status on any of the TCI personality traits (ANCOVA, with age and gender as covariates; results not shown). In the bipolar group, 31 (42.5\%) subjects had a comorbid diagnosis of alcoholism. Forty four of the 73 bipolar subjects $(60.3 \%)$ presented a diagnosis of at least one anxiety disorder. Dual comorbidity (both alcoholism and anxiety disorder) was present in 21 (28.8\%) of these patients. Nineteen (26\%) subjects had no comorbidity with either alcoholism or anxiety disorder. Details of the clinical characteristics of the bipolar group are displayed in Table 1 .

\subsection{Effects of diagnosis of bipolar disorder on personality traits}

ANCOVA showed that bipolar patients scored significantly higher on novelty seeking $\left(\mathrm{F}_{(1,132)}=29.6 ; \mathrm{p}<0.001\right)$, harm avoidance $\left(\mathrm{F}_{(1,132)}=86.4 ; \mathrm{p}<0.001\right)$ and self-transcendence $\left(\mathrm{F}_{(1,132)}=22.3 ; \mathrm{p}<0.001\right)$ than healthy individuals. The bipolar patients scored significantly lower on self-directedness $\left(\mathrm{F}_{(1,132)}=181.5 ; \mathrm{p}<0.001\right)$ and cooperativeness $\left(\mathrm{F}_{(1,132)}=28.8\right.$; $\mathrm{p}<0.001)$. Bipolar patients did not differ significantly from healthy individuals on reward dependence $\left(F_{(1,132)}=0.8 ; p=0.39\right)$ and persistence $\left(F_{(1,132)}=2.5 ; p=0.12\right)$. The means and S.D. for each dimension score for each of these groups are displayed in Table 2.

In the bipolar patients, self-directedness was negatively correlated with depression severity as measured by the HDRS $(r=-0.23, p=0.049)$ and positively correlated with age $(r=0.24, p$ $=0.04)$. There were no other significant bivariate correlations between the TCI dimensions and age, depression or mania severity. Age at onset or number of hospitalizations had no correlations with any of the TCI dimension scores. Length of illness had a weak to moderate correlation with self-transcendence, after controlling for age $(r=0.27, p=0.033)$. In the healthy control group, age was positively correlated with self-transcendence $(r=0.44, p<0.001)$. 


\subsection{Effects of comorbid alcoholism and/or comorbid anxiety disorders on personality traits}

We studied the effects of comorbidity by dividing the bipolar sample according to the presence of comorbid alcoholism and/or anxiety disorder. Nineteen $(26 \%)$ patients presented no comorbid condition, $10(13.7 \%)$ presented only comorbid alcoholism, 23 (31.5\%) presented only comorbid anxiety disorder, and $21(28.8 \%)$ presented both comorbid alcoholism and anxiety disorder. These 4 subgroups did not statistically differ on age (ANOVA, $F_{(3,69)}=0.48$, $\mathrm{p}=0.7)$ and $\mathrm{YMRS}$ score $\left(\mathrm{F}_{(3,69)}=2.3, \mathrm{p}=0.09\right)$ as well as age at disease onset and length of illness, but were statistically different in the distribution of gender (Chi square test, $\mathrm{p}=0.007$ ) and HDRS score (ANOVA, $\left.\mathrm{F}_{(3,69)}=6.7, \mathrm{p}<0.001\right)($ Table 3 ).

ANCOVA, with age, gender and mood state (measured by HDRS and YMRS) as covariates, revealed that these 4 subgroups of bipolar patients statistically differ from each other on harm avoidance $\left(\mathrm{F}_{(3,65)}=3.6, \mathrm{p}=0.017\right)$, persistence $\left(\mathrm{F}_{(3,65)}=2.8, \mathrm{p}=0.047\right)$ and self-directedness $\left(\mathrm{F}_{(3,65)}=4.8, \mathrm{p}=0.004\right)$. These groups did not statistically differ on novelty seeking $\left(\mathrm{F}_{(3,65)}\right.$ $=2.6, \mathrm{p}=0.06)$, reward dependence $\left(\mathrm{F}_{(3,65)}=2.5, \mathrm{p}=0.06\right)$, cooperativeness $\left(\mathrm{F}_{(3,65)}=2.4, \mathrm{p}\right.$ $=0.07)$ and self-transcendence $\left(\mathrm{F}_{(3,65)}=1.7, \mathrm{p}=0.17\right)$.

Pairwise comparisons with Sidak adjustment for multiple comparisons showed that the bipolar patients with only comorbid anxiety disorder $(n=23)$ presented statistically higher scores on harm avoidance (mean \pm S.D.: $23.1 \pm 6.0$ versus $14.6 \pm 7.6, p=0.013$ ) and lower scores on self-directedness $(21.9 \pm 1.6$ versus $29.6 \pm 1.8, \mathrm{p}=0.013)$ than the bipolar patients without any comorbid disorders $(n=19)$. Bipolar patients with only comorbid alcoholism $(n=10)$ presented statistically lower scores on persistence than bipolar patients without any comorbid disorders ( $3.2 \pm 0.8$ versus $5.8 \pm 0.6, \mathrm{p}=0.044)$. Lastly, bipolar patients with dual comorbidity $(\mathrm{n}=21)$ presented statistically lower scores on self-directedness than bipolar patients without any comorbid conditions $(20.6 \pm 1.6$ versus $29.6 \pm 1.8, \mathrm{p}=0.004)$. There was no difference between these 4 groups on any of the other personality dimensions (Table 3 ).

\section{Discussion}

We found that bipolar patients present higher levels of novelty seeking, harm avoidance and self-transcendence and lower levels of self-directedness and cooperativeness than healthy individuals. In bipolar patients, self-directedness decreased as the depression severity increased. Self-transcendence increased as the length of illness increased, even after controlling for age. Moreover, we also found that bipolar patients with comorbid conditions such as alcoholism or anxiety disorders differed from bipolar patients without any comorbid condition on certain personality traits. Specifically, bipolar patients with comorbid alcoholism had lower levels of persistence than those bipolar patients who never had any comorbidity. Bipolar patients with comorbid anxiety disorder presented higher harm avoidance and lower selfdirectedness levels than those bipolar patients who never had any comorbidity. Lastly, bipolar patients with dual comorbidity presented lower scores of self-directedness than bipolar patients without comorbidities.

\subsection{Personality differences between bipolar patients and healthy individuals}

Regarding the temperament traits, we found higher levels of novelty seeking and harm avoidance in bipolar patients in comparison to healthy individuals. While higher harm avoidance has been consistently linked to mood disorders in general (Cloninger et al., 1994; Brown et al., 1992; Joffe et al., 1993; Hirano et al., 2002), and with bipolar disorder in particular (Blairy et al., 2000; Osher et al., 1996; Osher et al., 1999; Engstrom et al., 2004a; Evans et al., 2005), higher novelty seeking in bipolar patients compared to both unipolar patients and healthy individuals has been reported by one study (Young et al., 1995). In the same study, bipolar patients presented higher novelty seeking than unipolar patients, and both groups had higher 
harm avoidance than the healthy control group, indicating that the combination of higher novelty seeking and harm avoidance might be a characteristic of bipolarity. Individuals high in novelty seeking are described as exploratory, curious, impulsive, extravagant, enthusiastic and disorderly (Cloninger et al., 1994), features that resemble the characteristics of manic phases and also Kraepelin's original conception of temperament as a rudimentary form of the full blown illness (Kraepelin, 1976). We investigated effects of mood state in the bipolar group by performing bivariate correlations between scores of manic and depressive symptoms and the TCI dimension scores. Novelty seeking was not associated with any effect of mood state, which reinforces that higher levels of novelty seeking may characterize some bipolar patients.

Turning attention to the character traits, bipolar patients presented lower self-directedness and cooperativeness and higher self-transcendence than healthy individuals. Two other studies support the conclusion that bipolar patients differ from healthy individuals in self-directedness (Engstrom et al., 2004a; Evans et al., 2005). By definition, character traits are progressive and depend on the unique and multiple experiences an individual has throughout life. Therefore, we speculate whether manifestations of Axis I conditions have adverse consequences on the development and expression of character traits, explaining the lower levels of self-directedness in bipolar patients. Bipolar patients also presented higher levels of self-transcendence in comparison with healthy individuals, and moreover, self-transcendence had a positive correlation with length of illness. One study also showed higher self-transcendence scores in bipolar patients compared with healthy individuals (Evans et al., 2005). This character trait may confer adaptive advantages in face of suffering and death (Cloninger et al., 1994) and therefore, we speculate whether higher self-transcendence in bipolar patients represent an adaptive process of dealing with their condition. In Table 4, we present a representative summary of the major TCI findings in bipolar disorder from previous studies and we highlight those findings that are replicated by this present study.

\subsection{Personality differences in bipolar disorder with comorbid alcohol and/or anxiety disorders}

Alcoholic bipolar patients scored lower than non-alcoholic bipolar patients on persistence. Lower levels of persistence also are associated with a diagnosis of metamphetamine abuse (Hosak et al., 2004), but studies using the TCI found no association between alcohol abuse and persistence, in spite of findings of higher novelty seeking and lower self-directedness in alcoholic patients compared to healthy individuals (Basiaux et al., 2001; Le Bon et al., 2004). Persistence is related to the ability to persevere despite frustration and fatigue, and it is possible that bipolar patients with low persistence may have more difficulty in stopping alcohol use despite its adverse consequences. The same may be so for methamphetamine abuse. It is noteworthy that alcoholic bipolar patients presented numerically higher scores on novelty seeking and lower scores on self-directedness than bipolar patients without any comorbidity (Table 3), and there is a possibility that, due to the small sample size of this specific subgroup $(n=10)$, these numbers failed to reach statistical significance. In spite of the cross-sectional design of our study, it is very tempting to speculate whether lower persistence combined to higher novelty seeking (more risk taking behaviors) and lower self-directedness (less ability to control and regulate one's own behavior) might jointly predispose bipolar patients to develop alcohol use disorders, contributing to the high prevalence rates of alcoholism in this population.

Bipolar patients with comorbid anxiety disorders presented higher harm avoidance and lower self-directedness than bipolar patients without any anxiety disorder. This combination (higher harm avoidance and lower self-directedness) also characterizes the differences between anxiety disorder patients and healthy individuals (Lyoo et al., 2001; Ball et al., 2002; Pélissolo et al., 2002), therefore suggesting that the presence of anxiety explains more this combination than a bipolar component. Alternatively, if a principal component of bipolar disorder entails anxiety, 
then the similar profile could equally reflect an intrinsic biological characteristic that is common to anxiety and bipolar disorders. In this regard, some authors defend that anxiety/ depression may be a primary dimension rather than a co-occurrence of conditions in bipolar disorder (Swann et al., 2001). Another consideration is the potential confounding influence of depression severity. Bipolar patients with only comorbid anxiety disorder and bipolar patients with both comorbid alcoholism and anxiety presented the highest HDRS scores (see Table 3 ). Therefore, the more severe depression exhibited by the patients with these comorbid disorders could influence their self directedness scores. To examine this possibility, we performed ANCOVA while statistically holding depression severity constant by including the HDRS score as a covariate. The bipolar patients with alcohol and anxiety comorbidity still presented significantly lower scores on self-directedness.

Because the subdivision of the bipolar sample resulted in small subgroups of bipolar patients, with differences in certain demographic characteristics, such as sex distribution and intensity of depressive symptoms, we should state that any interpretation of these findings should be considered speculative at this time. However, it is important to note that our findings of differences in personality traits according to the presence of comorbid alcoholism or comorbid anxiety disorder in bipolar patients are consistent with previous studies showing that personality, at least to some extent, mediates the comorbidity phenomena in psychiatric disorders (Battaglia et al., 1996; Khan et al., 2005). In Table 4, we show some major TCI findings in alcohol/drug use disorders and anxiety disorders to better illustrate the complex inter-relationship between bipolar disorder, psychiatric comorbidity and personality traits.

One limitation of this study is the high frequency of symptomatic bipolar patients, and therefore, a possible contamination of self-reports by the current mood state. The issue of whether changes in the levels of personality traits observed in the context of a mood episode reflect state artifacts rather than genuine changes in personality or in the enduring pattern that characterizes a 'trait' has been a long-standing controversy (Costa Jr. et al., 2005). Some authors contend that the clinical mood state influences patients' self-perceptions and therefore, should be considered when symptomatic patients are evaluated (Hirschfeld et al., 1983), whereas others claim that patients' responses during different illness phases are internally consistent, have a high agreement with ratings from informants and may actually reflect real personality changes intrinsic to the episode (Bagby et al., 1998; Costa Jr. 2005). Regarding the TCI, some studies demonstrate a possible mood state effect for harm avoidance, selfdirectedness and cooperativeness in unipolar patients (Brown et al., 1992; Chien and Dunner, 1996; Kleifield et al., 1994; Hirano et al., 2002). On the other hand, Sato et al (2001)

demonstrated that the TCI has a high internal consistency and a factor structure that is robust against mild to moderate states of depression (as it is in this study). Although we studied mostly symptomatic BD patients, our results replicated most of the previous findings of temperament and character traits in euthymic BD subjects (Young et al., 1995; Osher et al., 1996; Osher et al., 1999; Blairy et al., 2000; Engstrom et al., 2004a; Evans et al., 2005). Therefore, although mood state effects are possible, it is unlikely that they explain our findings of personality differences between BD patients and healthy individuals. Another approach to control the effect of current mood state and further investigate any possible interactions between mood episodes and personality in $\mathrm{BD}$ would be by comparing the bipolar patients across different types of episodes (euthymic, major depressive episode, manic/mixed episode). Our euthymic BD subgroup had a small size $(\mathrm{n}=6)$ however, which made such comparison unfeasible. This is nevertheless an important and under-studied area, and future research is necessary to address it.

Other limitations of this study include the relatively small sample size, especially in the comorbid subgroups, the cross-sectional design, the lack of comparison with groups of alcoholic patients and anxiety disorder patients (without bipolar disorder). However, this study 
has also important strengths. We replicated previous findings of higher levels of novelty seeking and harm avoidance in bipolar patients in comparison to healthy individuals, and this combination might indicate a "bipolarity" feature. Because temperament traits are supposedly heritable, stable and manifest early in life, these findings might point to core biological features of personality that precede disease onset and that suffer less influence from the disease process, and therefore, help in the search for genetic and neurobiological roots of bipolar disorder. We also demonstrated that the presence of psychiatric comorbidities in bipolar disorder might be associated with specific personality traits.

In conclusion, bipolar patients exhibit a different personality structure from healthy individuals. Novelty seeking, harm avoidance, self-directedness and cooperativeness are the personality traits most closely related to bipolar disorder. The combination of high novelty seeking and high harm avoidance might be a characteristic of bipolarity. Personality traits may contribute, at least in part, to the development of comorbidity in bipolar disorder, and alternatively, the presence of comorbidity in bipolar disorder may affect some personality traits. Comorbid alcoholism is associated with lower levels of persistence in bipolar disorder. Presence of comorbid anxiety disorder in bipolar disorder is associated with higher harm avoidance and lower self-directedness scores. Recognition of these associations may bring new insights to the underlying phenomena involved in the etiology of comorbidity in bipolar disorder and lead to a more appropriate management of these patients.

\section{References}

Angst, J. Temperament and personality types in bipolar patients: a historical review. In: Marneros, A.; Angst, J., editors. Bipolar disorders: 100 years after Manic-Depressive Insanity. Dordrecht, The Netherlands, Boston: Mass Klewer Publishers; 2000. p. 175-199.

Akiskal HS, Hirschfeld RMA, Boghos IY. The relationship of personality to affective disorders. A critical review. Archives of General Psychiatry 1983;40:801-810. [PubMed: 6344834]

Bagby RM, Rector NA, Bindseil K, Dickens SE, Levitan RD, Kennedy SH. Self-report ratings and informants' ratings of personalities of depressed outpatients. American Journal of Psychiatry 1998;155:437-438. [PubMed: 9501762]

Ball S, Smolin J, Shekhar A. A psychobiological approach to personality: examination within anxious outpatients. Journal of Psychiatric Research 2002;36:97-103. [PubMed: 11777498]

Basiaux P, Le Bon O, Dramaix M, Massat I, Souery D, Mendlewicz J, et al. Temperament and Character Inventory (TCI) personality profile and sub-typing in alcoholic patients: a controlled study. Alcohol and Alcoholism 2001;36:584-587. [PubMed: 11704626]

Battaglia M, Przybeck TR, Bellodi L, Cloninger CR. Temperament dimensions explain the comorbidity of psychiatric disorders. Comprehensive Psychiatry 1996;37:292-298. [PubMed: 8826693]

Blairy S, Massat I, Staner L, Le Bon O, Van Gestel S, Van Broeckhoven C, et al. 5HT2a receptor polymorphism gene in bipolar disorder and harm avoidance personality trait. American Journal of Medical Genetics 2000;96:360-364. [PubMed: 10898915]

Brown SL, Svrakic DM, Przybeck TR, Cloninger CR. The relationship of personality to mood and anxiety states: a dimensional approach. Journal of Psychiatric Research 1992;26:197-211. [PubMed: 1432846]

Chien AJ, Dunner DL. The Tridimensional Personality Questionnaire in depression: state versus trait issues. Journal of Psychiatric Research 1996;30:21-27. [PubMed: 8736463]

Cloninger, CR.; Przybeck, TR.; Svrakic, DM.; Wetzel, RD. Missouri Center for Psychobiology of Personality. St Louis, MO: Washington University Press; 1994. The Temperament and Character Inventory (TCI): A guide to its development and use.

Cloninger CR, Svrakik DM, Przybeck TR. A psychobiological model of temperament and character. Archives of General Psychiatry 1993;50:975-990. [PubMed: 8250684]

Cloninger, CR.; Svrakik, DM. Personality disorders. In: Sadock, BJ.; Sadock, VA., editors. Kaplan \& Sadock's Comprehensive Textbook of Psychiatry. Lippincott Williams \& Wilkins; 2005. p. 2064-2104. 
Conway KP, Kane RJ, Ball SA, Poling JC, Rounsaville BJ. Personality, substance of choice, and polysubstance involvement among substance dependent patients. Drug and Alcohol Dependence 2003;71:65-75. [PubMed: 12821207]

Costa PT Jr, Bagby RM, Herbst JH, McCrae RR. Personality self-reports are concurrently reliable and valid during acute depressive episodes. Journal of Affective Disorders 2005;89:45-55. [PubMed: 16203041]

Engstrom C, Brandstrom S, Sigvardsson S, Cloninger CR, Nylander PO. Bipolar disorder. II: Personality and age of onset. Bipolar Disorders 2003;5:340-348. [PubMed: 14525554]

Engstrom C, Brandstrom S, Sigvardsson S, Cloninger CR, Nylander PO. Bipolar disorder I. Temperament and character. Journal of Affective Disorders 2004a;82:131-134. [PubMed: 15465586]

Engstrom C, Brandstrom S, Sigvardsson S, Cloninger CR, Nylander PO. Bipolar disorder. III: Harm avoidance a risk factor for suicide attempts. Bipolar Disorders 2004b;6:130-138. [PubMed: 15005751]

Evans L, Akiskal HS, Keck PE Jr, McElroy SL, Sadovnick AD, Remick RA, et al. Familiality of temperament in bipolar disorder: support for a genetic spectrum. Journal of Affective Disorders 2005;85:153-168. [PubMed: 15780686]

First, MB.; Gibbon, M.; Spitzer, RL.; Williams, JBW. New York, NY: State Psychiatric Institute, Biometrics Research Department; 2002. Structured Clinical Interview for DSM-IV-TR Axis I Disorders.

Hamilton, M. Hamilton Psychiatric Rating Scale for Depression. In: Guy, W., editor. ECDEU Assessment Manual for Psychopharmacology. Washington DC: U.S. Department of Health, Education and Welfare; 1976. p. 179-192.

Hirano S, Sato T, Narita T, Kusunoki K, Ozaki N, Kimura S, et al. Evaluating the state dependency of the Temperament and Character Inventory dimensions in patients with major depression: a methodological contribution. Journal of Affective Disorders 2002;69:31-38. [PubMed: 12103449]

Hirschfeld RM, Klerman GL, Clayton PJ, Keller MB, McDonald-Scott P, Larkin BH. Assessing personality: effects of the depressive state on trait measurement. American Journal of Psychiatry 1983;140:695-699. [PubMed: 6846626]

Hosak L, Preiss M, Halir M, Cermakova E, Csemy L. Temperament and character inventory (TCI) personality profile in metamphetamine abusers: a controlled study. European Psychiatry 2004;19:193-195. [PubMed: 15196599]

Joffe RT, Bagby RM, Levitt AJ, Regan JJ, Parker JD. The Tridimensional Personality Questionnaire in major depression. American Journal of Psychiatry 1993;150:959-960. [PubMed: 8494077]

Kessler RC, Crum RM, Warner LA, Nelson CB, Schulenberg J, Anthony JC. Lifetime co-occurrence of DSM-III-R alcohol abuse and dependence with other psychiatric disorders in the National Comorbidity Survey. Archives of General Psychiatry 1997;54:313-321. [PubMed: 9107147]

Khan AA, Jacobson KC, Gardner CO, Prescott CA, Kendler KS. Personality and comorbidity of common psychiatric disorders. British Journal of Psychiatry 2005;186:190-196. [PubMed: 15738498]

Kleifield EI, Sunday S, Hurt S, Halmi KA. The effects of depression and treatment on the Tridimensional Personality Questionnaire. Biological Psychiatry 1994;36:68-70. [PubMed: 8080908]

Kraepelin, E. In Manic-Depressive Insanity and Paranoia. New York: Arno Press; 1976. Fundamental States; p. 117-132.

Le Bon O, Basiaux P, Streel E, Tecco J, Hanak C, Hansenne M, et al. Personality profile and drug of choice: a multivariate analysis using Cloninger's TCI on heroin addicts, alcoholics, and a random population group. Drug and Alcohol Dependence 2004;73:175-182. [PubMed: 14725957]

Lyoo IK, Lee DW, Kim YS, Kong SW, Kwon JS. Patterns of temperament and character in subjects with obsessive-compulsive disorder. Journal of Clinical Psychiatry 2001;62:637-641. [PubMed: 11561937]

McElroy SL, Altshuler LL, Suppes T, Keck PE Jr, Frye MA, Denicoff KD, et al. Axis I psychiatric comorbidity and its relationship to historical illness variables in 288 patients with bipolar disorder. American Journal of Psychiatry 2001;158:420-426. [PubMed: 11229983]

Osher Y, Cloninger CR, Belmaker RH. TPQ in euthymic manic-depressive patients. Journal of Psychiatric Research 1996;30:353-357. [PubMed: 8923339] 
Osher Y, Lefkifker E, Kotler M. Low persistence in euthymic manic-depressive patients: a replication. Journal of Affective Disorders 1999;53:87-90. [PubMed: 10363670]

Pélissolo A, André C, Pujol H, Yao SN, Servant D, Braconnier A, et al. Personality dimensions in social phobics with or without depression. Acta Psychiatrica Scandinavica 2002;105:94-103. [PubMed: 11939958]

Regier DA, Farmer ME, Rae DS, Locke BZ, Keith SJ, Judd LL, et al. Comorbidity of mental disorders with alcohol and other drug abuse. Results from the Epidemiologic Catchment Area (ECA) Study. Journal of the American Medical Association 1990;264:2511-2518. [PubMed: 2232018]

Rogers G, Joyce P, Mulder R, Sellman D, Miller A, Allington M, et al. Association of a duplicated repeat polymorphism in the 5'-untranslated region of the DRD4 gene with novelty seeking. American Journal of Medical Genetics. Part B. Neuropsychiatric Genetics: the official publication of the International Society of Psychiatric Genetics 2004;126:95-98.

Sato T, Narita T, Hirano S, Kusunoki K, Goto M, Sakado K, Uehara T. Factor validity of the temperament and character inventory in patients with major depression. Comprehensive Psychiatry 2001;42:337341. [PubMed: 11458309]

Simon NM, Otto MW, Wisniewski SR, Fossey M, Sagduyu K, Frank E, et al. Anxiety disorder comorbidity in bipolar disorder patients: data from the first 500 participants in the systematic treatment enhancement program for bipolar disorder (STEP-BD). American Journal of Psychiatry 2004;161:2222-2229. [PubMed: 15569893]

Staner L, Hilger C, Hentges F, Monreal J, Hoffmann A, Couturier M. Association between novelty seeking and the dopamine D3 receptor gene in bipolar patients: a preliminary report. American Journal of Medical Genetics 1998;81:192-194. [PubMed: 9613861]

Swann AC, Janicak PL, Calabrese JR, Bowden CL, Dilsaver CS, Morris DD. Structure of mania: depressive, irritable, and psychotic cluster with different retrospectively-assessed course patterns of illness in randomized clinical trial participants. Journal of Affective Disorders 2001;67:123-132. [PubMed: 11869759]

Young LT, Bagby MR, Cooke RG, Parker JDA, Levitt AJ, Joffe RT. A comparison of Tridimensional Personality Questionnaire dimensions in bipolar patients and unipolar depression. Psychiatry Research 1995;58:139-143. [PubMed: 8570765]

Young TC, Biggs JT, Ziegler VE, Meyer DA. A rating scale for mania: reliability, validity and sensibility. British Journal of Psychiatry 1978;133:429-435. [PubMed: 728692]

\section{Acknowledgements}

This work was partly supported by grants MH 01736, MH 068662, MH 068766, RR020571, UTHSCSA GCRC (M01RR-01346), NARSAD, the Krus Endowed Chair in Psychiatry (UTHSCSA), and the Veterans Administration (VA Merit Review). The authors of this paper do not have any commercial associations that might pose a conflict of interest in connection with this manuscript. 
Table 1

Clinical characteristics of the bipolar group

\begin{tabular}{|c|c|}
\hline Characteristics & Bipolar Patients $(n=73)$ \\
\hline Age of onset of bipolar disorder (mean \pm S.D.) & $20.9 \pm 9.3$ \\
\hline Length of illness (mean \pm S.D.) & $17.3 \pm 12.3$ \\
\hline Lifetime alcoholism ( $n, \%)$ & $31(42.5)$ \\
\hline Abuse & $6(8.2)$ \\
\hline Dependence & $25(34.2)$ \\
\hline Lifetime anxiety disorder (any) ( $n, \%)$ & $44(60.3)$ \\
\hline Panic disorder & $20(27.4)$ \\
\hline Agoraphobia & $2(2.7)$ \\
\hline Social phobia & $13(17.8)$ \\
\hline Specific phobia & $8(11)$ \\
\hline Obsessive compulsive disorder & $8(11)$ \\
\hline Post traumatic stress disorder & $16(21.9)$ \\
\hline Generalized anxiety disorder & $15(20.5)$ \\
\hline Anxiety disorder NOS & $3(4.1)$ \\
\hline \multicolumn{2}{|l|}{ Mood state (according to SCID) (n, \%) } \\
\hline Euthymic & $6(8.2)$ \\
\hline Major depressive episode & 45 (61.6) \\
\hline Mixed episode & $10(13.7)$ \\
\hline Manic episode & $12(16.4)$ \\
\hline
\end{tabular}

Abbreviations: HAMD (Hamilton Depression Rating Scale); YMRS (Young Mania Rating Scale), NOS (Not Otherwise Specified); SCID (Structured Clinical Interview for Diagnosis). 
Table 2

TCI dimension scores in bipolar patients and healthy individuals*

\begin{tabular}{|l|c|c|c|c|}
\hline Dimensions & $\begin{array}{c}\text { Bipolar patients } \\
(\mathbf{n}=\mathbf{7 3})\end{array}$ & $\begin{array}{c}\text { Healthy individuals } \\
(\mathbf{n}=\mathbf{6 3})\end{array}$ & $\mathbf{F}_{(\mathbf{d f})}$ & P value \\
\hline & Mean \pm S.D. & Mean \pm S.D. & & \\
\hline Temperament traits & & & & \\
\hline Novelty seeking & $23.0 \pm 6.6$ & $17.5 \pm 5.3$ & $29.6_{(1,132)}$ & $<0.001$ \\
\hline Harm avoidance & $19.7 \pm 7.4$ & $9.5 \pm 5.6$ & $86.3_{(1,132)}$ & $<0.001$ \\
\hline Reward dependence & $15.8 \pm 4.0$ & $16.6 \pm 4.2$ & $0.8_{(1,132)}$ & 0.4 \\
\hline Persistence & $5.0 \pm 2.3$ & $5.6 \pm 2.1$ & $2.5_{(1,132)}$ & 0.12 \\
\hline Character traits & & & & $181.5_{(1,132)}$ \\
\hline Self-directedness & $23.8 \pm 8.1$ & $39.0 \pm 4.2$ & $28.8_{(1,132)}$ & $<0.001$ \\
\hline Cooperativeness & $31.6 \pm 7.0$ & $37.0 \pm 4.2$ & $22.3_{(1,132)}$ & $<0.001$ \\
\hline Self-transcendence & $19.2 \pm 6.8$ & $13.4 \pm 6.2$ & & \\
\hline
\end{tabular}

* Analysis of covariance (ANCOVA), with age and gender as covariates 


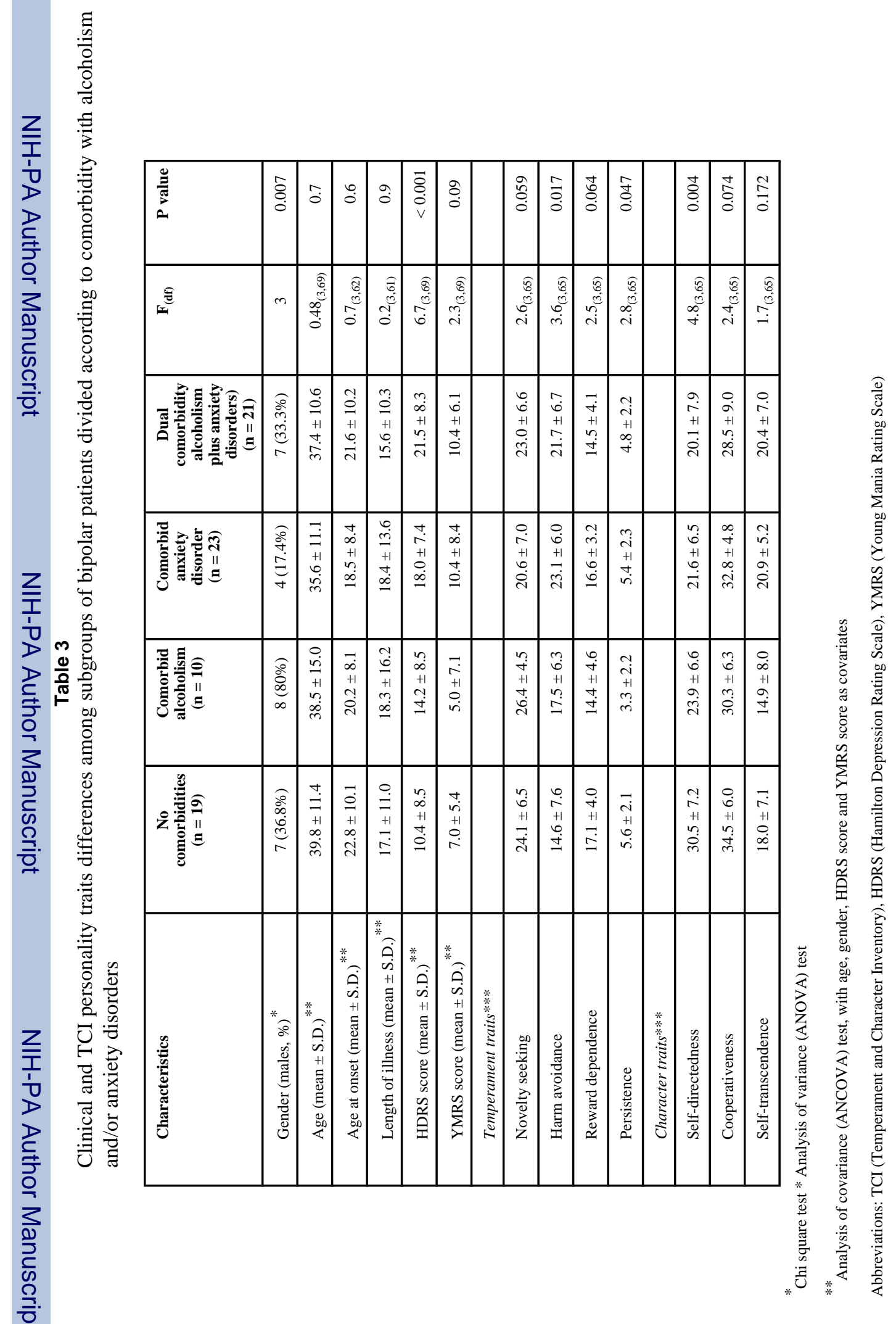


Table 4

Summary of major findings of the TCI in controlled studies of bipolar disorder, alcohol/drug use disorders and anxiety disorders

\begin{tabular}{|c|c|c|}
\hline Study & Sample size & Findings \\
\hline \multicolumn{3}{|l|}{ Bipolar disorder } \\
\hline Young et al., 1995 & 45 euthymic BD patients versus 100 age matched $\mathrm{HC}$ & $\begin{array}{l}\uparrow \text { novelty seeking } \\
\uparrow \text { harm avoidance }\end{array}$ \\
\hline Osher et al., 1996 & 50 euthymic BD patients ${ }^{*}$ & $\begin{array}{l}\uparrow \text { harm avoidance } \\
\uparrow \text { reward dependence } \\
\downarrow \text { persistence }\end{array}$ \\
\hline Osher et al., 1999 & 25 euthymic BD patients versus 25 gender and ethnic matched $\mathrm{HC}$ & $\begin{array}{l}\downarrow \text { novelty seeking } \\
\downarrow \text { persistence }\end{array}$ \\
\hline Engstrom et al., 2004a & 100 euthymic BD patients versus 100 age and gender matched $\mathrm{HC}$ & $\begin{array}{l}\uparrow \text { harm avoidance } \\
\downarrow \text { reward dependence } \\
\downarrow \text { self-directedness } \\
\downarrow \text { cooperativeness }\end{array}$ \\
\hline Evans et al., 2005 & $159 \mathrm{BD}$ patients versus $63 \mathrm{HC}^{* *}$ & $\begin{array}{l}\uparrow \text { novelty seeking } \\
\uparrow \text { harm avoidance } \\
\downarrow \text { self-directedness } \\
\downarrow \text { cooperativeness } \\
\uparrow \text { self-transcendence } \\
\end{array}$ \\
\hline \multicolumn{3}{|c|}{ Alcohol/drug use disorders } \\
\hline Basiaux et al., 2001 & 38 alcoholic patients versus 47 age and gender matched $\mathrm{HC}$ & $\begin{array}{l}\uparrow \text { novelty seeking } \\
\downarrow \text { self-directedness }\end{array}$ \\
\hline Le Bon et al., 2004 & 37 alcoholic patients versus 83 age matched $\mathrm{HC}$ & $\begin{array}{l}\uparrow \text { novelty seeking } \\
\uparrow \text { harm avoidance } \\
\downarrow \text { self-directedness } \\
\downarrow \text { self-transcendence }\end{array}$ \\
\hline Hosak et al., 2004 & 41 metamphetamine abusers versus 35 age and gender matched $\mathrm{HC}$ & $\begin{array}{l}\uparrow \text { novelty seeking } \\
\uparrow \text { harm avoidance } \\
\downarrow \text { persistence } \\
\downarrow \text { self-directedness } \\
\downarrow \text { cooperativeness } \\
\uparrow \text { self-transcendence }\end{array}$ \\
\hline \multicolumn{3}{|l|}{ Anxiety disorders } \\
\hline Lyoo et al., 2001 & 40 obsessive-compulsive disorder patients versus age, gender and IQ matched HC & $\begin{array}{l}\downarrow \text { novelty seeking } \\
\uparrow \text { harm avoidance } \\
\downarrow \text { self-directedness }\end{array}$ \\
\hline Ball et al., 2002 & 120 patients with anxiety and depressive disorders versus $17 \mathrm{HC}{ }^{* * *}$ & $\begin{array}{l}\uparrow \text { harm avoidance } \\
\downarrow \text { self-directedness }\end{array}$ \\
\hline Pelissolo et al., 2002 & 126 social phobia patients versus 602 subject-community sample & $\begin{array}{l}\uparrow \text { harm avoidance } \\
\downarrow \text { self-directedness } \\
\downarrow \text { cooperativeness } \\
\downarrow \text { self-transcendence }\end{array}$ \\
\hline
\end{tabular}

Abbreviations: BD (bipolar disorder); HC (healthy controls). Those findings that are replicated by our present study are highlighted in bold italic.

* No control group; comparisons made with general population (U.S. norms)

**

Four subjects in the BD group had a diagnosis of schizoaffective disorder, bipolar type ***

Post hoc analyses showed that statistical differences in harm avoidance and self-directedness remained after comparing each separated group of anxiety disorder to the $\mathrm{HC}$ group 